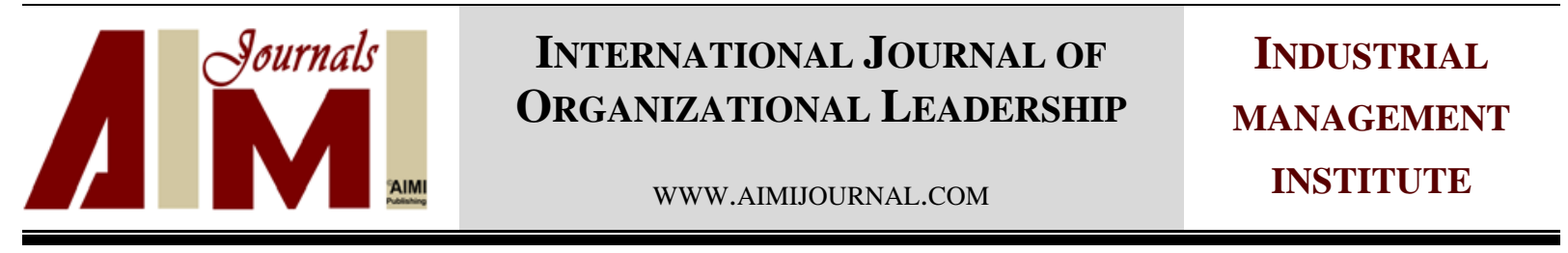

\title{
Risk analysis in the management of urban construction projects from the perspective of the employer and the contractor
}

\author{
Mohammad Taghipour, Fatemeh Seraj*, Mohammad Amir Hassani, Sharareh \\ Farahani Kheirabadi
}

ABA Institute of Higher Education

\begin{abstract}
Keywords:

Construction Project, Risks, Employer, Contractor

Correspondence:

Fseraj_ie@yahoo.com

Imbalance between anticipated and actual progress in the development of urban construction projects suggests that there are many obstacles and risks which not only causes the urban management be unsustainable, but the reconstruction and development of urban space is also seriously threatened. In this study, the library research on issues related to the risk of construction projects was done, then some interviews were conducted with experts and managers informed and involved in the projects, and finally questionnaires were distributed to identify and classify the impact of the risks of the implementation of the construction projects. After analyzing the data, the results indicated that the experts listed the most significant risks as the delays in the payment of contractors' claims and statements due to the lack of handling financial instruments, the governance of relationships rather than rules in the tenders resulting from employer actions, low commitment to the quality of work provided by their subcontractors, failure to complete the detail engineering by foreign contractors on time, weaknesses in contractors' financial resources, and offering lower prices than reasonable by contractors to win the tender. All of these require special attention and other kinds of risks are important at the next level. Finally, the solutions for eliminating or reducing risks in highrisk areas have been offered to provide tranquility for contractors and employers.
\end{abstract}

(C)AIMI Journals

\section{Introduction}

In order to fulfill the projects better, the project management was created and its general concept is the use of knowledge, skills, tools and techniques necessary to meet the needs and 
expectations of stakeholders. Project management is the art of directing and coordinating human resources and materials throughout the life of a project by using modern management techniques of which the most important objectives include the reduction of cost and time and improving the quality of the projects. However, the project at any time is confronted with obvious and hidden risks that may have a significant impact on the cost and time. Therefore, in order to maximize the positive events and minimize the consequences of disasters, the risk management emerged as one of the key areas in the project management. Much of each country's capital, especially in developing countries is devoted to the construction projects and infrastructure and a factor in economic growth and development in any society is the success in the implementation of construction projects. Delay and lack of progress in the implementation of urban construction projects which causes the lack of sustainable urban management is indicative of the fundamental problems and obstacles in the implementation of valuable urban projects and the reconstruction and development of urban space is seriously threatened and it can be named as a crisis of construction projects (Vatankhah, 2003). The main problem faced by most of the large projects is the delay in different phases and completion of the project. Delay is the action or event that took longer to perform specific operations referred to in the contract and it appears by prolonging the duration of practice or postponing of the start date (Schumacher, 1995). If the operation of the projects is delayed, it will cause the loss of the national assets and some of them will lose their economic and technical justification.

\section{The Definition of Risk and the Risk Management}

Risk is the potentiality which can cause problems in the implementation of projects and also achieving the predetermined goals. Risk is inherent in all projects and whereas it cannot be removed completely, in order to reduce the negative effects, it is imperative to identify, analyze them in detail, and manage them effectively. Risk refers to the probability of occurrence of an unknown event which is going to cause some problems. In other words, the risk depends on the situation where actual results of one thing are likely to be affected by something unknown, while the probability of occurrence and its effects is precisely predetermined (Smith, 1999).

Williams and Heins (1971) defined risk as a deviation in the specified period in a certain position. If only one event and deviation is possible, therefore, the risk is zero, and if many 
other events are possible, the risk is not zero at all; and, the greater the magnitude of the deviation, the greater the risk.

Risk is the measurement and probability of not achieving the pre-determined goals of the project. In general, the risk is the lack of knowledge of an event in the future (Kerzner, 2006).

According to the American project management standard "PMBOK", risk in projects is the imminent unknown events or circumstances which influences negatively or positively the objectives of the project. Each of these events or conditions has specific causes and detectable outcomes. The consequences of these events impact directly time, cost, and the quality of the project (Aladpush, 2003). In fact, risk management is one of the major themes of the project (Eunchang, Yongtae \& Gye, 2009). Most organizations involved in the project consider it as a key field (Elmar \& Mark, 2010). Risk management is the systematic process to identify, analyze and respond to project management which includes maximization of the probability of positive events and results and minimization of the likelihood of harmful accidents and their consequences (Prasanta, 2010). In brief, risk assessment is the process of estimating the probability of occurring an event (favorable or unfavorable) and its effect (Zeng \& Smith, 2007).

\section{Categorization of Risks}

In the literature on risk, the various categories of risks were presented. Here, from the relevant references for the risks of a project, in terms of the occurrence of the risk and its various influences, the following categories of risks are considered (Sadeghinia \& Shakeri, 2011).

- Risks related to Performance, Purpose, Quality and Technical Issues of the Project: In this category of risk, the implementation and completion of the projects are affected. When technical problems increase the cost and the time of completing the project, operational risks lead to the risk in cost and time.

- Time Risk: This risk would delay the deadline of the completion of the project. This class of risk affects directly the risk of the cost and the operational risk.

- Cost Risk: This kind of risk would deviate the project cost from the approved budget for the project. Certainly, the cost risk is closely associated with the time risk. This risk can lead to operational risk.

- Increasing Risk: The risks themselves are less important, but their accumulation creates an important risk. For example, a small increase in the cost of a contractor's work does not affect 
the funds. When the project has a wide arrange of contractors, the final outcome of these increases is a very important risk.

- Catastrophic Risk: This risk includes all risks that individually have significant effects and affects other risks. The possibility of their occurrence is very low but their impact is very high. For example, the critical technology for the disposal of waste needs special equipment.

- Environmental, Safety, and Health Risk: These risks include those harmful effects which the project has on the environment. Serious incidents of this kind of risk impact the budget seriously.

\section{Explanation of the process of risk analysis and its variables}

In this process, the risky potential event based on the potential effects of each of them on the objectives of the project is prioritized. The likelihood and consequences of the realization of the anticipated risks is qualitative rather than quantitative and after creating a risk matrix based on two variables mentioned, the priority risks is determined.

These two variables for each risk according to "PMBOK Guide" are identified and assessed as follow:

- Probability: The probability of identified risks is reflected in the future while implementing the project. The possibility of risk with words and linguistic variables are displayed. Then, these words are shown in a quantitative scale.

- The Severity of the Impact: It is the effect size of the risk on the project objectives. Anticipated objectives include completing a project and providing products in time, cost planning, design quality, and given scope of work. Therefore, a risk may affect each of these objectives. Table 1 and Table 2 quantify the probability and impacts of risk on project and Figure 1 shows risk matrix. 


\begin{tabular}{|c|c|c|c|c|c|c|}
\hline \multicolumn{7}{|c|}{ Impact } \\
\hline \multirow{6}{*}{ 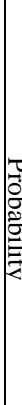 } & M & $\mathrm{H}$ & $\mathrm{H}$ & VH & VH & VH \\
\hline & $\mathrm{L}$ & M & $\mathrm{H}$ & $\mathrm{H}$ & VH & $\mathrm{H}$ \\
\hline & $\mathrm{L}$ & $\mathrm{L}$ & M & $\mathrm{H}$ & $\mathrm{H}$ & M \\
\hline & VL & L & $\mathrm{L}$ & M & $\mathrm{H}$ & $\mathrm{L}$ \\
\hline & VL & VL & L & $\mathrm{L}$ & M & VL \\
\hline & VL & $\mathrm{L}$ & M & $\mathrm{H}$ & VH & \\
\hline
\end{tabular}

Figure 1. Risk matrix

Table 1

A Guide to Quantify the Probability of Risks

\begin{tabular}{|c|c|c|c|c|}
\hline \multicolumn{5}{|c|}{ Probability } \\
\hline It is ensured very much. & $>80 \%$ & 0.9 & $\mathrm{VH}$ & Very high \\
\hline A high probability for its occurrence is expected. & $60-80 \%$ & 0.7 & $\mathrm{H}$ & High \\
\hline It is likely to happen. & $40-60 \%$ & 0.5 & M & Medium \\
\hline There is less probability to occur. & $20-40 \%$ & 0.3 & $\mathrm{~L}$ & Little \\
\hline It occurs very rarely. & $<20 \%$ & 0.1 & VL & Very little \\
\hline
\end{tabular}

Table 2

Guide to Quantify the Extent of the Risk Effect

Impact

\begin{tabular}{lllc}
\hline Possible failure to complete the project & 0.9 & VH & Very high \\
\hline Excessive delays set for delay penalty & 0.7 & High & M \\
\hline Delay in project more than the estimated contract & 0.5 & L & Ledium \\
\hline Delays caused by rising costs and compensable resources & 0.3 & VL & Very little
\end{tabular}

\section{The Role of the Main Factors in the Development of Construction Projects}

Various studies have been conducted on the risk of construction projects and then the role of various factors has been recognized. Some of these roles in terms of their significant effect are unique. After reviewing the investigations, it can be concluded that the role of the main factors of project (employers and contractors) is of great significance.

For example, some employers believe in quality of performance against reasonable expenses. However, some of them are not willing to accept or participate in taking risk even with the objective of increasing the quality of the project implementation; especially in recent years, employers have come to the conclusion that putting the contractors in financial pressure cannot lead the best quality of the work; thus, they are partially flexible to take the risk. However, sometimes both employers and contractors behave in such a way that creates a great risk. 


\section{Purpose and Significance of the Study}

The aim of this study after the assessment and classification of risk and before sorting them on the basis of the actions of one group of officials (employer and contractor) was to identify the impact and likelihood of the risk in six categories of risk through the qualitative analysis by employing the experiences of managers and experts in urban projects during a field study. In other words, the purpose was to analyze the risk associated with these two key factors which interfere with the efficient implementation of construction projects in Tehran. It should be noted that in order to judge fairly and despite the employer's and contractor's different understanding of the project management and the risk management and increasing the reliability and accuracy (creating a successful circumstance for the implementing projects in order to achieve the optimal performance in the projects regarding three dimensions of time, quality and cost), the questionnaires related to the contractor's risk should be filled by senior executives in employers and managers company and the questionnaire about the risks created by the employer's actions should be filled out by experts in popular contracting companies of the country. Therefore, potentially hazardous events should be identified through a risk matrix and finally it should offer some solutions for eliminating or reducing those risks to increase the productivity of the projects.

\section{The Literature Review}

Since risks are unavoidable in almost any type of construction projects and it is inherent in all human attempts including construction activities and the risk factors involved are diverse and varied, therefore, managing construction project risks is considered as compulsory for any project to be successful. Thus, various studies have been conducted on the risk assessment by using various methods. Some of these studies investigated the delays in an industry or in a particular country. Among them we can refer to the studies done on the reasons of delays and increased costs in construction projects in Nigeria (Mansfield, Ugwu, \& Doran, 1994), identifying the reasons for delays in the construction industry in Lebanon (Mezher, Jamali, \& Carine, 2002), study of large projects in Saudi Arabia (Assaf, Mohammed, \& Muhammad, 1995), the reports of progress in 164 construction projects and 28 projects in highway construction project in 1999-1996 in Jordan (Odeh \& Battaineh, 2002), and investigations in the causes of delay in implementing the Plan and Budget Organization, factors contributing to delays of airport projects (Ghotbi, 1999). 
Gao, Sung, and Zhang (2011) referred to the risk management and risk management capability building in small and medium sized enterprise (SMEs). Risk management capability is produced by SMEs without formal structures and knowledge and such firms are more prone to implement informal procedures to improve risk management capability. They stated that the role of cognitive capital is necessary for the risk management capability building of SMEs and that cognitive capital has a principle role in acquiring structural and relational capital.

Sharma and Swain (2011) intended to recognize and categorize the kinds of construction project risks, to assess the level of construction project risks and ultimately, to classify the techniques possible to decrease the construction project risks.

The pressure for developing quality while lowering time and costs puts considerable emphasis on managing risk in projects. Following this, numerous models and techniques have been advanced and used in practice; thus, there is a considerable demand for analyzing when and how each of them should be utilized. Simultaneously, knowledge related to risk management becomes necessary to efficiently deal with the intricacy of projects (Cagliano, Grimaldi, \& Rafele, 2015).

Liu, Meng, and Fellows (2015) examined how culture affects contractors' risk management in construction projects. The results revealed that national culture plays an essential important role in contractor's risk management and project risks are observed and organized variously in different national cultures.

Muchfirodin, Guritno, and Yuliando (2015) investigated to identify and mitigate risks in tobacco supply chain based on risk management principles in ISO 31000. The mitigation plan was made by using tool of analytical network process (ANP). The results showed that avoidance risk at farmer level is weather, capital access, and the price and quantity. At the middlemen level, it refers to quality contamination, capital access, and the price and quantity. And, at higher level, avoidance risks are supplier quality variances, capital access, and the price and quantity. Based on ANP method, the fit strategy to overcome the price instability was the development of cultivation technology that focuses on seed technology.

Salawu and Abdullahb (2015) in their study presented a systematic approach for assessing risk management capability of the construction organizations executing some projects in Nigeria. The research findings indicated that the risk management capability level of construction organizations at those projects is novice. However, they are more mature in risk management resources particularly in experience dimension. 
A procedure of risk management in projects tends to be rational chain of practices by which decision-agents arrange and implement actions and directs the results to maintain the project execution under particular circumstances such as time, cost, and quality parameters. Rodrigues-da-Silva and Crispim (2014) suggested a guideline for choosing the best practices considering the organizational maturity and project complexity, a theoretical framework to organize those practices to each stage of the project and to each project RM process.

In an exploratory study of enterprise risk management (ERM), Lundqvist (2014) determined the integral components of ERM based on how firms essentially put into operation ERM dimensions. The outcome is the recognition of four components of ERM implementation; two components related to the general internal environment and control activities of the firm, one component identified risk management activities of the firm and one component dealt with the describing features of ERM implementation. All four components must be implemented to have well-implemented ERM.

Applying Standard and Poor's newly possible risk management rating, McShane, Nair, and Rustambekov (2011) discovered evidence of a positive relationship between increasing levels of traditional risk management (TRM) capability and firm value but no extra boost of value for firms achieving a higher ERM rating.

Risk perception and risk attitude for understanding individual's risk management are of prime importance. Van Winsena, de Mey, Lauwers, Van Passel, Vancauteren and Wauters (2014) suggested a model supposing the option to perform specific risk management strategies to be driven by both concepts of risks and risk attitude. They discovered that the concept of major farm business risks has no substantial effect on the purpose of using any of the risk strategies under study but risk attitude have an important effect. So, it is the general risk attitude that influences intended risk strategies to be used.

Thun Druke and Hoenig (2011) empirically explored supply chain risk management in small and medium-sized enterprises (SME). The analyses indicated that SME predominantly centers on reactive instruments that absorb risks through the production of redundancies instead of preventing risks.

Wang (2014) examined the process of public-private partnership (PPP) models evolution in infrastructure development based on project sponsors' risk management. The analysis showed that public institutions' risk management can effectively explain the PPP evolution. 


\section{Method}

Risk identification is the process of determining and documenting of elements that is provided in a comprehensive database. There are several methods to identify project risks, some of which are the analysis of a checklist of risks obtained from similar projects and other information sources in the past or identifying the method of the judgment of experts obtained directly by experts who have similar experiences.

In this study, firstly, the first method (the analysis of a checklist of risks) was used. This method was prepared by using various information resources in construction projects as well as results obtained from previous research. Some of them were removed because of similarities and some others were integrated.

Then, the risks were divided into two groups: The risks associated with contractors according to the employer's perspective included 22 kinds of risk, as well as risks related to the employers according to the contractor's perspective included 19 kinds of risks. Then, the checklists of projects were re-evaluated by the experts.

The next step is to assess the risk matrix to determine the class of risk, probability of occurrence, and the extent of its impact on the project through a questionnaire. To know the views of active people in the management of engineering projects and to increase the response validity, the questionnaires were distributed among people employed in surveillance systems and management of contractor companies such as Ben Amon construction companies and Adak Gostaran construction companies and some other questionnaires were distributed among employers working on ongoing projects in the municipality of Tehran and Sharif University of Technology. Based on the data obtained, the risk matrix for each of the risks was created and factors based on their risk were prioritized. And, their quality status and impact was determined in probability matrix.

\section{Results}

After collecting the questionnaires and experts' comments, the risks associated with the employers and contractors were listed as follows:

Identified Risks Associated with the Employers:

A. Failure to determine the appropriate time based on scientific studies

B. Changing employer's needs to change the volume of work, scope of work, service sector, and side borders project 
C. Technical weaknesses in the management and evaluation of studies done by a consultant that would lead to the implementation of the projects with technical problems

D. Lack of timely elimination of opponents (real estate, facilities, traffic, and green space)

E. Not taking into consideration the contractor's facilities at the time of contract

F. Wrong attitude of employers towards contractors

G. Delays in the supply of materials, delivery of workshops, and basis points, maps, or things the employer is obliged to do

H. Technical weaknesses of employer's representative in coordinating between the consulting engineers and contractor and timely solving the technical and construction problems

I. Failure to provide adequate funding and financial credit resources

J. Failure to facilitate communication between the consultant and contractor

K. Lack of personnel's and employer experts' technical knowledge and insufficient information about planning and project control

L. Inadequate supervision and control of the process of implementation

M. Lack of attention to experience, capabilities, and efficiency of contractors and contracting based on the lowest price

N. Delay in the payment of contractors' claims and statements due to weakness in handling financial documents

O. The speeds of data transmission to design consultant

P. Hurrying in project inauguration and its reverse results

Q. Governance of relations rather than rules in the system of tenders

R. Changes in different employer management levels in the duration of project implementation

S. Lack of technological knowledge and insufficient information of related personnel and experts from planning and project control

Identified Risks Associated with the Actions of Contractors:

A. The lack of contractors' comprehensive and large-scale planning

B. disproportion of subcontractors' commitments with the company's commitments for the employer 
C. Weakness in the number and experience of technical and executive contractors

D. Weakness in the project management in the contractor system for the completion of the project on time

E. Weakness of the contractor in the construction and executive management

F. Late arrival of documents of the detailed design contractor

G. Mismatch between the machinery and facilities and the type and volume of work

$\mathrm{H}$. The level of control and optimal guidance of contractors by the engineering sector

I. The problems of workshop mobilization such as processing time, space, and facilities

J. Lack of large contracting companies

K. Discrepancy among contractors

L. Low commitment of the subcontractors to the quality of work

M.Failure to complete the detail engineering by foreign contractors on time

$\mathrm{N}$. Dispute between the Iranian contractor and the foreign contractor which leads to suspension of providing domestic goods by the contractor

O. Shortage of experienced contracting companies in EPC contracts

P. Mismatch between the goods provided by EP contractors with contractors' executive programs

Q. Weakness in the contractors' financial resources

R. Lack of recognition of the work by the contractor

S. Lack of attention to the hints of consultant and employers regarding technical specifications and use of inappropriate materials

T. Lack of timely informing of the contractors, consultants, and employers to solve the problem

U. The way of selecting subcontractors from different engineering sectors

V. Offering lower prices than reasonable one by contractors to win the tender

In the next step, the variables and risks associated with each class of risk such as determining the class of the risk, the probability of occurrence, and impact on project were identified by professionals and experts in the field and finally the position of each risk was identified in the evaluation matrix. Tables 3 and Table 4 show the risk factors resulting from the actions of contractors and employers. 
Table 3

Risk Factors Resulting from the Actions of Contractors

\begin{tabular}{ccccc}
\hline ID & Risk Category & Probability & Impact & Position in Evaluation Matrix \\
\hline A & A & $40-60 \%$ & 0.7 & $\mathrm{H}$ \\
B & A & $20-40 \%$ & 0.5 & $\mathrm{~L}$ \\
C & A & $40-60 \%$ & 0.9 & $\mathrm{H}$ \\
D & B & $40-60 \%$ & 0.7 & $\mathrm{H}$ \\
E & A & $40-60 \%$ & 0.9 & $\mathrm{H}$ \\
F & B,D & $60-80 \%$ & 0.7 & $\mathrm{H}$ \\
G & A.C & $40-60 \%$ & 0.7 & $\mathrm{H}$ \\
H & A,D & $20-40 \%$ & 0.5 & $\mathrm{~L}$ \\
I & A,B & $40-60 \%$ & 0.5 & $\mathrm{M}$ \\
J & A,E & $20-40 \%$ & 0.9 & $\mathrm{H}$ \\
K & A,D & $60-80 \%$ & 0.7 & $\mathrm{H}$ \\
L & A,D & $60-80 \%$ & 0.9 & $\mathrm{VH}$ \\
M & B,E & $60-80 \%$ & 0.9 & $\mathrm{VH}$ \\
N & A,E & $40-60 \%$ & $\mathrm{H}$ \\
O & A & $60-80 \%$ & 0.9 & $\mathrm{H}$ \\
P & A,D & $40-60 \%$ & 0.7 & $\mathrm{H}$ \\
Q & B,E & $60-80 \%$ & 0.7 & $\mathrm{VH}$ \\
R & A,E & $40-60 \%$ & 0.9 & $\mathrm{H}$ \\
S & B,C,E & $60-80 \%$ & 0.9 & $\mathrm{VH}$ \\
T & D & $60-80 \%$ & 0.9 & $\mathrm{H}$ \\
U & A,D & $20-40 \%$ & 0.7 & $\mathrm{~L}$ \\
V & A,C,F & $40-60 \%$ & 0.5 & $\mathrm{H}$ \\
\hline
\end{tabular}

Table 4

Risk Factors Resulting from the Actions of Employers

\begin{tabular}{ccccc}
\hline ID & Risk Category & Probability & Impact & Position in Evaluation Matrix \\
\hline A & A,C & $<20 \%$ & 0.9 & $\mathrm{H}$ \\
B & C,D & $40-60 \%$ & 0.7 & $\mathrm{~L}$ \\
C & A,E & $20-40 \%$ & 0.7 & $\mathrm{H}$ \\
D & C,F & $40-60 \%$ & 0.5 & $\mathrm{H}$ \\
E & A,C & $60-80 \%$ & 0.7 & $\mathrm{H}$ \\
F & B,C & $40-60 \%$ & 0.7 & $\mathrm{H}$ \\
G & A & $20-40 \%$ & 0.7 & $\mathrm{H}$ \\
H & A,D & $40-60 \%$ & 0.7 & $\mathrm{~L}$ \\
I & A,B,C & $40-60 \%$ & 0.9 & $\mathrm{M}$ \\
J & D & $20-40 \%$ & $\mathrm{H}$ \\
K & A,D & $60-80 \%$ & 0.5 & $\mathrm{H}$ \\
L & A,E & $40-60 \%$ & 0.7 & $\mathrm{VH}$ \\
M & A,E & $40-60 \%$ & 0.9 & $\mathrm{VH}$ \\
N & A,B, C,D & $>80 \%$ & 0.9 & $\mathrm{H}$ \\
O & B,C & $60-80 \%$ & 0.9 & $\mathrm{H}$ \\
P & A,E,F & $60-80 \%$ & 0.7 & $\mathrm{H}$ \\
Q & A,E & $60-80 \%$ & 0.7 & $\mathrm{VH}$ \\
R & B,C & $40-60 \%$ & 0.9 & $\mathrm{H}$ \\
S & A,B,C & $40-60 \%$ & 0.7 & $\mathrm{VH}$ \\
\hline
\end{tabular}

Figures 2, 3, and 4 show the frequency of risk class and their position in risk assessment matrix for better analysis. 


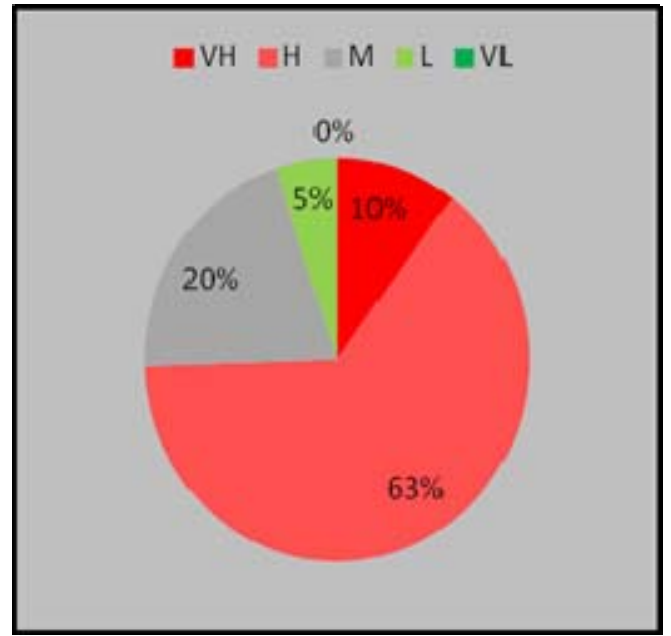

Figure 2. Frequency of risks between employer and contractor

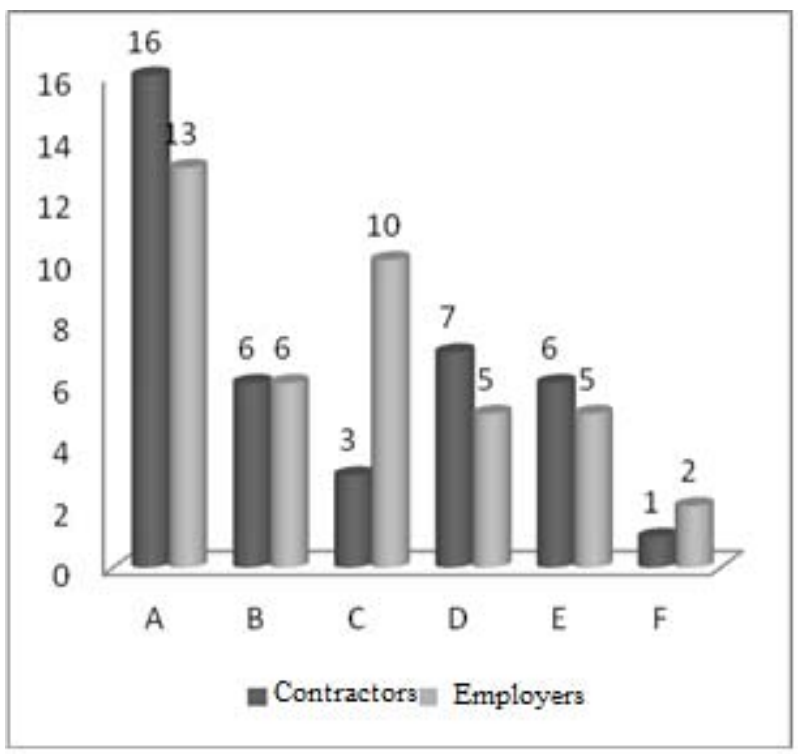

Figure 3. Frequency of risks associated with employers in the evaluation matrix

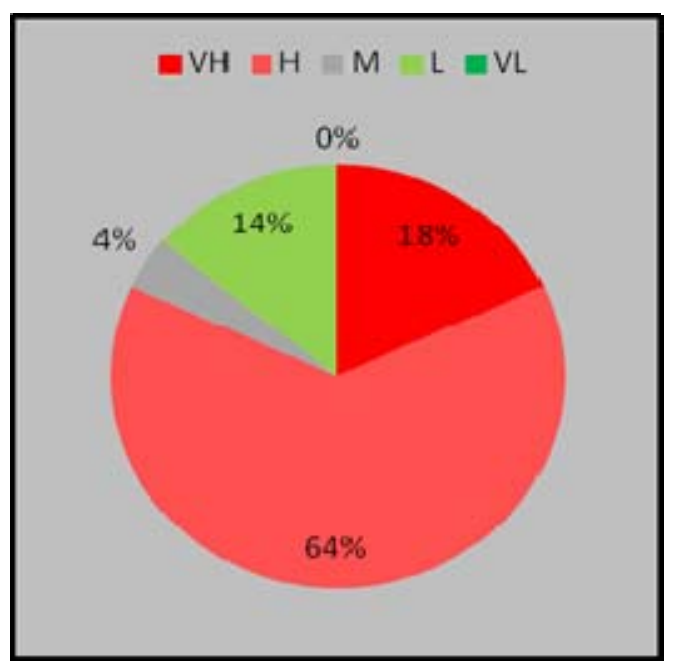

Figure 4. Frequency of risks associated with contractors in the evaluation matrix 
Figure 2 shows the results based on the frequency of risk class in each class. As can be seen, the risks associated with contractors were more in class A, and secondly, most of the risks belonged to increasing risks and the risks of class D. Although these risks were not of prime importance, but little accumulation of them created an important risk. The risks associated with the employers, the risks of class A were leading ones and the risks of class $\mathrm{C}$ including risks of costs were the second. Therefore, it can be concluded that contractors and employers created risks mostly related to performance, purpose, quality, and technical affairs of projects; in the second place, contractors created increasing risk and employers were often guilty of risks that had the greatest impact on the cost of the project.

Also, in the second type of classification of risk analysis, according to the Figure 3 and Figure 4 and by assessing the position of risks in the areas of warning risk to moderate risk, it can be concluded that firstly, risks from the category $\mathrm{H}$ with a maximum frequency in both groups were equally striking, and secondly, the risk of $\mathrm{VH}$ or dangerous risks belonged to the contractors group mostly which required special attention from project managers. With these figures, it can be concluded that contractors mainly created risks that leads to risks which had either low or high impact and the intermediate risks were not significant. This was exactly the opposite in employers who mainly create risks with the highest frequency after risk category $\mathrm{H}$, category $\mathrm{M}$ or intermediate category.

\section{Discussion}

From the analyzed risks, since the most risky or dangerous risks were located in the dangerous or red area and because of their importance in the implementation of the project, they were separated to eliminate or reduce their effects and some solutions were presented as follows:

\section{Delay in the Payment of Contractors' Claims and Statements due to Weakness in} Handling Financial Documents: Not only it causes financial damage to the contractors but also the amount payable by the employer increases because of the addition of fine resultant from inflation. On the other hand, it increases the cost of the project due to the delay caused by the event. To prevent this, conversion of non-regular and inefficient archive into a regular and justifiable system using an effective information system in project will have a significant impact on them. Contractors can also choose employers who have a coherent regulatory system and top funds. By following up the process of implementation of past projects which 
other contractors had with these employers, it is practical to study well the way of their management in the financial system.

Governance of Relations rather than Rules in the System of Tenders: Although eliminating the bidding procedures and delegation of authority to managers and organizations in general can reduce costs and save time and since the selection of contractor is on the basis of pre-selected list regarding the background of cooperation, so, making decision will have a higher reliability. In addition, this could be the most important reason for governing relations and violation of the laws and the competitive pressure by influential contractors. Also, the influence of natural and legal persons may affect the normal process of choosing the right contractor. In these situations, showing the follow-ups in accordance with the usual procedure to ensure that the contractors have access to the continuous and exclusive access to contracts is of great importance. Creating conditions for the contractors to give probable suggestions and simultaneously respecting principles and criteria can be effective for contracting affaires.

Failure to Complete the Detail Engineering by Foreign Contractors on Time: After completion of the basic engineering, detail engineering activities will start. Detail engineering, which is based on the exclusive features of basic engineering, is started by licenser (foreign engineers) and has two main sections of providing detailed drawings and tender documents and as a sensitive stage often faced with many problems. Lack of coordination and cooperation of foreign engineers engaged in providing detail engineering plans for the project and extending the time of implementing project will lead to significant financial losses. At this stage, due to having monopoly of specific information by licenser practically Iranian engineers depend largely on licenser. Obviously, if relations between these two are not normal, detail engineering activities will be stopped seriously which ultimately affect the project completion time. In this regard, a contract is signed for supervising the implementation of detail engineering work of the project. Also, one can choose the right foreign contractor (as a licenser having the technical knowledge of the project) who has a very strong management system and this makes feasible the timely progress of the project and timely operation of the project.

Low Commitment of Subcontractors to the Quality of Work: Adequate supervision and tendency of monitoring systems towards the project's quality issues, detailed reporting, and consciously choosing subcontractors while being formal and considering official all of the obligations in the legal agreements may lead to removing or reducing the aforementioned 
risk. Since that risk has a direct impact on the quality and cost of the project and it is considered as the increasing risk of project, it requires special attention of project managers.

Weaknesses in the Contractor's Financial Resources: Most contracting companies due to specific regulations of some banks are not able to timely receive the required guarantees; therefore, it interferes with the progress of the project. On the other hand, it lead to the lack of regulations which give authority to the banks that by relying on the signed agreements they can give some per cent of contract amount as loan to contractors with low interest to solve their liquidity problem. In the absence of adequate financial resources, contractors are recommended not to participate in the bidding. Organizations need to pay attention to the revising terms of the selection of contractors, regarding the criteria of financial capability and administrative records.

Offering Lower Prices than Reasonable one by Contractors to Win the Tender: Since in tenders, the selection of the contractor takes place based on the lowest price offer, therefore, some contractors offer unreasonable and low prices and they achieve top rank and win the tender. And, since the highest demands of doing a project by a contractor is its financial gain or the profit made by a project, in practice, to advance the project, they have to reduce the quality or use the leverage management called claims. These claims eventually lead to two interrelated factors, namely change and delay that in any case it will lead to the waste of time and cost which are an important aspect for the project. First, in such circumstances, the employer should determine the basic amount of the bid with a realistic view and then consider the flexible prices offered by contractors on the basis of documentation and scientific and rational reasons. Employers in addition to the cost of the project should pay more attention to the quality and duration of the project. Finally, it should be noted that since risk is an integral part of all projects, logical acceptance of risk and creating a culture of rational participation instead of accusing the parties due to the existence of common goals such as optimized implementation of the project based on time, cost, and quality triangle can play a significant role in its control and dramatically improve the implementation of the projects. Besides, a significant reduction in the use of leverage claims can take place.

\section{Conclusion}

Since risk is an integral part of all projects, the purpose of risk identification is to complete the project with minimal changes regarding the original schedule and the considerable progress. The present study specifically examined urban construction projects and it can be 
concluded that the main risks affecting the urban projects were the types of risk that affected implementation issues, purpose, quality and technical affairs of projects, costs, and increasing risks. Based on the results of the surveys in different groups, six factors including low commitment of the subcontractors to the quality of work, failure to complete the detail engineering by foreign contractors on time, lack of contractors' financial resources, contractors' offering of lower prices than reasonable one to win the tender, delay in the payment of contractors' claims and statements due to weakness in handling financial documents, governance of relations rather than rules in the system of tenders can be regarded as risks with the greatest impact on the project implementation process which need special attention. In order to control them in urban construction projects, some solutions are suggested, namely tendency of monitoring systems towards the project's quality issues, detailed reporting and consciously choosing subcontractors, signing a contract for monitoring the task of detail engineering of project by licensors, lack of contractor's participation in tender in terms of the weakness in financial resources, flexible pricing by contractors based on a basic and reasonable amount by providing documentation and scientific reasons, choosing employers with a coherent regulatory system and high affordability, conversing non-regular and inefficient archive into a regular and justifiable system. Also, it is suggested to show the follow-ups in accordance with the usual procedure to ensure that the contractors have access to the continuous and exclusive access to contracts. Besides, creating conditions for the contractors to give probable suggestions and simultaneously respecting principles and criteria can be effective for contracting affaires.

\section{References}

Aladpush, H. (2003). Standard of project management knowledge. Tehran: Hamiye Porogheh Press.

Assaf, S. A., Mohammed, A. K., \& Muhammad, A. H. (1995). Causes of delay in large building construction projects. Journal of Management in Engineering, 11(2), 45-50.

Cagliano, A.C., Grimaldi, S., \& Rafele, C. (2015). Choosing project risk management techniques: A theoretical framework. Journal of Risk Research, 18(2), 232-248.

Elmar, K., \& Mark, H. (2010). Deliberate ignorance in project risk management. International Journal of Project Management, 28, 245-255.

Eunchang, L., Yongtae, P., \& Jong G. S. (2009). Large engineering project risk management using a Bayesian belief network. Expert Systems with Applications, 36, 5880-5887.

Gao, S. S., Sung, M. C., \& Zhang, J (2011). Risk management capability building in SMEs: A social capital perspective. International Small Business Journal, 31(6), 677-700.

Ghotbi, Z. (1999). Evaluation of causes of delayed construction projects of Iran's Airport network (Unpublished master's thesis). Iran Management and Productivity Study Center (IMPSC), Tehran, Iran.

Kerzner, H. (2006). Project management: A system approach to planning, scheduling \& controlling (9 $9^{\text {th }}$ ed.). Hoboken, New Jersey: John Wiley \& Sons. 
Liu, J., Meng, F., \& Fellows, R. (2015). An exploratory study of understanding project risk management from the perspective of national culture. International Journal of Project Management, 33(3), 564-575.

Lundqvist, S. A. (2014). An exploratory study of enterprise risk management: Pillars of ERM. Journal of Accounting, Auditing \& Finance, 29(3), 393-429.

Mansfield, N. R., Ugwu, O. O., \& Doran, T. (1994). Causes of delay and cost overruns in Nigerian construction projects. International Journal of Project Management, 12(4), 254-260.

McShane, M. K., Nair, A., \& Rustambekov, E. (2011). Does enterprise risk management increase firm value? Journal of Accounting, Auditing, \& Finance, 26(4), 641-658.

Mezher, T., Jamali, D., \& Zreik, C. (2002). The role of financial institutions in the sustainable development of Lebanon. Sustainable Development, 10(2), 69-78.

Muchfirodin, M., Guritno, A. D., \& Yuliando, H. (2015). Supply chain risk management on Tobacco Commodity in Temanggung, Central Java (Case study at farmers and middlemen level). Agriculture \& Agricultural Science Procedia, 3, $235-240$

Odeh, A. M., \& Battaineh, H. T. (2002). Causes of construction delay: Traditional contracts. International Journal of Project Management, 20(1), 67-73.

Prasanta, K. D. (2010). Managing project risk using combined analytic hierarchy process and risk map. Applied Soft Computing Journal, 10(4), 990-1000.

Rodrigues-da-Silva, L. H., \& Crispim, J. A. (2014). The project risk management process, a preliminary study. Procedia Technology, 16, 943-949.

Sadeghinia, S., \& Shakeri, A. (2011). Promoting safety level of projects benefiting from risk management. Official Website of Hormozgan Rural Water and Wastewater Company.

Salawu, R. A., \& Abdullah, F. (2015). Assessing risk management maturity of construction organizations on infrastructural project delivery in Nigeria. Procedia - Social and Behavioral Sciences, 172, 643-650.

Schumacher, L. (1995). Quantifying and apportioning delay on construction projects. Journal of Cost Engineering, 37(2), $11-13$.

Sharma, S. K., \& Swain, N. (2011). Risk management in construction projects. Asia-Pacific Business Review, 7(2), 107120.

Smith, N. J. (1999). Managing risk in construction projects. Oxford: Blackwell Science Publishers.

Thun, J. H., Druke, M., \& Hoenig, D. (2011). Managing uncertainty - an empirical analysis of supply chain risk management in small and medium-sized enterprises. International Journal of Production Research, 49(18), 5511-5525.

Van Winsen, F., de Mey, Y. Lauwers, L., Van Passel, S., Vancauteren, M., \& Wauters, E. (2014). Determinants of risk behaviour: Effects of perceived risks and risk attitude on farmer's adoption of risk management strategies. Journal of Risk Research, 17(8), 1-23.

Vatankhah, R. (2003). Investigating the causes of delayed construction projects: A case study of renewal project of the country's school (Unpublished master's thesis). Tarbiat Modarres University, Iran.

Wang, Y. (2014). Evolution of public-private partnership models in American toll road development: Learning based on public institutions’ risk management. International Journal of Project Management, 33, 684-696.

Williams, H. W., \& Heins, R. M. (1971). Risk management and insurance. New York: McGraw-Hill.

Zeng, J., \& Smith N. J. (2007). Application of fuzzy based decision making methodology to construction project risk assessment. International Journal of Project Management, 25(6), 589-600. 